\title{
Influence of End Groups on Dendrimer Rheology and Conformation
}

\author{
Brian M. Tande, ${ }^{\dagger}$ Norman J . Wagner, ${ }^{*, \dagger}$ and Young H. Kim ${ }^{\ddagger}$ \\ Center for Molecular and Engineering Thermodynamics, Department of Chemical Engineering, \\ University of Delaware, Newark, Delaware 19716, and Dupont Central Research and Development, \\ Experimental Station, Wilmington, Delaware 19880-0328
}

Received May 23, 2002; Revised Manuscript Received March 7, 2003

\begin{abstract}
Poly(propyleneimine) (PPI) dendrimers and their end-functionalized derivatives are studied with steady and dynamic rheology to determine the influence of specific end groups. Fourth- and fifthgeneration PPI dendrimers exhibit constant shear viscosities over a wide range of shear rates. Functionalizing the molecular end groups with methyl and benzyl acrylate monomers increases the glass transition temperature and leads to a significant elastic modulus and nonlinear rheological behavior at high shear rates. The zero-shear viscosity, corrected for the shift in glass transition, exhibits a unique maximum with molecular weight. The fractional free volume derived from the thermal rheological measurements is independent of the end-group derivatization and substantially larger than that for linear polymers.
\end{abstract}

\section{Introduction}

Dendrimers and hyperbranched polymers (HBPs) have been proposed for use in a variety of potential applications from drug delivery agents and catalysts to composites and rheological modifiers. ${ }^{1-6}$ The numerous end groups in dendritic molecules provide opportunities for creating unique copolymers with core-shell architectures or for creating highly cross-linked networks, for example. These applications will be aided by a more detailed understanding of how the mol ecular structure and conformation of dendrimers affect their macroscopic properties, such as rheology and thermodynamic phase behavior.

Besides being a relevant material property for applications, the rheological behavior of dendrimers and HBPs can provide information about dendrimer intermolecular interactions as well as molecular conformation. In general, the rheological properties of dendrimer melts are expected to depend on the architecture (number of branches, generation number, etc.), the chemical nature of the molecule, and the end groups. The effects of branching architecture and spacer length on the flow properties of highly branched molecules have been studied by Sendijarevic and McHugh. ${ }^{7}$ In their work, comparisons between the rheological properties of both well-ordered dendrimers and randomly branched HBPs demonstrated that the degree of branching is an important rheological parameter. It was also observed that dendrimers and compact HBPs do not show rheological evidence of entanglements, unlike more open HBPs at higher molecular weights. Other studies by U ppuluri et al. ${ }^{8}$ and Farrington et al. ${ }^{9}$ have examined the viscosity of dendrimers as a function of generation number, finding that the mol ecular weight dependence of the viscosity approaches the behavior of linear, unentangled polymers for high generation numbers (i.e., $\eta \sim \mathrm{M}_{\mathrm{w}}{ }^{1}$ ). One noteworthy difference with linear polymers is that dendritic polymers have a significantly higher fractional free volume, which can be attributed to a preponderance of end groups.

\footnotetext{
† University of Delaware.

‡ Dupont Central Research and Development, Experimental Station.

* Corresponding author. E-mail: wagner@che.udel.edu.
}

In contrast to these earlier studies, our work focuses on determining the influence of the chemical nature of the molecular end groups on the conformation and rheol ogy of dendrimers. Previous work with acetylated PPI dendrimers focuses on solution structure, rheol ogy, and interactions with linear polymers in water. ${ }^{10,11}$ In this work, we have examined both the solution architecture and melt rheology of fourth- and fifth-generation poly(propyleneimine) (PPI) dendrimers derivatized with two different acrylate monomers. The results of density measurements along with steady and dynamic rheology are analyzed to draw connections between copolymer composition, molecular structure, and bulk mechanical behavior.

\section{Experiment}

Materials. Poly(propyleneimine) dendrimers (DSM, Netherlands) of fourth and fifth generation were used in this study, denoted as G4 PPI and G5 PPI, respectively. These molecules were reacted via a Michael addition with two different esters of acrylic acid, benzyl acrylate and methyl acrylate (SigmaAldrich), using a previously published synthesis. ${ }^{12}$ The details of the synthesis for the fourth-generation case are given below. These methyl and benzyl ester functionalized products are denoted as MA or BA. Spectroscopy shows that the dendrimers were successfully and completely derivatized, with two acrylate molecules reacting with every amine end group. The fifth-generation products were synthesized in an identical manner to the G4 products and have virtually identical spectroscopic data.

Table 1 lists the properties of the six molecules that were studied. The molecular weights listed are ideal, calculated using the known number of end groups and molecular weight of the original material. It can be seen that the functionalization substantially increases the molecular weight of the dendrimers, a consequence of the numerous end groups in the molecule. Also, the number of end groups is doubled upon functionalization since each amine end group in the PPI dendrimer is reacted with two acrylate monomers.

Synthesis of G4 PPI/MA. G4 PPI $(5.4 \mathrm{~g}, 1.54 \mathrm{mmol})$ and $\mathrm{LiCl}(30 \mathrm{mg})$ were dissolved in methanol $(35 \mathrm{~mL})$ in a $50 \mathrm{~mL}$ flask and cooled to $0{ }^{\circ} \mathrm{C}$ with an ice-water bath. Methyl acrylate (14.3 g, $166 \mathrm{mmol}$ ) was added to the stirred solution in a dropwise manner over a period of $10 \mathrm{~min}$. The reaction vessel was removed from the ice-water bath and allowed to stir overnight at room temperature. The solvent was evaporated under reduced pressure, and the product was stripped with dichloromethane $(3 x)$ in order to remove the excess 
Table 1. Characterization of PPI Dendrimers and Derivatives

\begin{tabular}{|c|c|c|c|c|c|}
\hline sample & $\begin{array}{l}\text { no. of } \\
\text { end } \\
\text { groups }\end{array}$ & $\begin{array}{l}\mathrm{M}_{\mathrm{w}} \\
(\mathrm{Da})\end{array}$ & $\begin{array}{c}\mathrm{T}_{\mathrm{g}} \\
\left( \pm 1^{\circ} \mathrm{C}\right)\end{array}$ & $\begin{array}{c}\text { melt } \\
\text { density } \\
\left(21^{\circ} \mathrm{C}\right) \\
\left(\mathrm{g} / \mathrm{cm}^{3}\right)\end{array}$ & $\begin{array}{c}\eta_{0}^{*}\left(0^{\circ} \mathrm{C}\right) \\
(\mathrm{Pa} \mathrm{s})\end{array}$ \\
\hline G4 P & 32 & 3 & -6 & 0.98 & 18 \\
\hline G4 PF & 6 & & -5 & & \\
\hline G4 PPI/BA & 6 & 138 & -39 & & $1290 \pm 10$ \\
\hline 5 5DI & Ci & & -66 & & $614 \pm 4$ \\
\hline $1 / M$ & 128 & 181 & -5 & & $2510 \pm$ \\
\hline G5 PPI/ BA & 128 & 27892 & -37 & 1.04 & $13750 \pm 90$ \\
\hline
\end{tabular}

methanol and unreacted methyl acrylate. The methyl ester functionalized dendrimer, G4 PPI/MA (12.1 g, 87\%), was obtained as a yellowish, viscous liquid.

${ }^{1} \mathrm{H} \mathrm{NMR}\left(\mathrm{CDCl}_{3}\right): \delta=3.6\left(\mathrm{~s}, 192 \mathrm{H}, \mathrm{COOCH}_{3}\right), 2.7(\mathrm{t}, 128 \mathrm{H}$, $\left.\mathrm{NCH}_{2} \mathrm{CH}_{2} \mathrm{COOCH}_{3}\right), 2.3\left(\mathrm{t}, 128 \mathrm{H}, \mathrm{NCH}_{2} \mathrm{CH}_{2} \mathrm{COOCH}_{3}\right), 2.3(\mathrm{~m}$, $\left.240 \mathrm{H}, \mathrm{NCH}_{2} \mathrm{CH}_{2} \mathrm{CH}_{2} \mathrm{~N}\right), 1.6\left(\mathrm{~m}, 12 \mathrm{OH}, \mathrm{NCH}_{2} \mathrm{CH}_{2} \mathrm{CH}_{2} \mathrm{~N}\right)$. IR: $v\left(\mathrm{~cm}^{-1}\right)=2949(\mathrm{C}-\mathrm{H}) ; 1738(\mathrm{C}=\mathrm{O})$.

Synthesis of G4 PPI/BA. A solution of G4 PPI (4.9 g, 1.40 $\mathrm{mmol}$ ) and $\mathrm{LiCl}(30 \mathrm{mg})$ in methanol $(35 \mathrm{~mL}$ ) was stirred and cooled in an ice-water bath. Benzyl acrylate (18.9 g, 117 $\mathrm{mmol}$ ) was added in a dropwise manner over a period of 10 min. The reaction vessel was removed from the ice-water bath and al lowed to stir overnight at room temperature. Two liquid phases were formed, the bottom of which was purified via evaporation under reduced pressure and dichloromethane extraction $(5 \times)$. The benzyl ester functionalized dendrimer, G4 PPI/ BA (17.5 g, 90\%), was obtained as a yellowish, viscous liquid.

${ }^{1} \mathrm{H} \mathrm{NMR}\left(\mathrm{CDCl}_{3}\right): \delta=7.1\left(\mathrm{~s}, 32 \mathrm{H}, \mathrm{COOCH}_{2} \mathrm{C}_{6} \mathrm{H}_{5}\right), 4.8(\mathrm{~s}$, $\left.128 \mathrm{H}, \mathrm{COOCH}_{2} \mathrm{C}_{6} \mathrm{H}_{5}\right), 2.5\left(\mathrm{t}, 128 \mathrm{H}, \mathrm{NCH}_{2} \mathrm{CH}_{2} \mathrm{COOCH}_{2} \mathrm{C}_{6} \mathrm{H}_{5}\right.$ ), 2.3 (t, $\left.128 \mathrm{H}, \mathrm{NCH}_{2} \mathrm{CH}_{2} \mathrm{COOCH}_{2} \mathrm{C}_{6} \mathrm{H}_{5}\right), 2.2\left(\mathrm{~m}, 240 \mathrm{H}, \mathrm{NCH}_{2}\right.$ $\left.\mathrm{CH}_{2} \mathrm{CH}_{2} \mathrm{~N}\right), 1.3\left(\mathrm{~m}, 12 \mathrm{OH}, \mathrm{NCH}_{2} \mathrm{CH}_{2} \mathrm{CH}_{2} \mathrm{~N}\right)$. IR: $v\left(\mathrm{~cm}^{-1}\right)=$ $3032(\mathrm{C}-\mathrm{H}) ; 2944(\mathrm{C}-\mathrm{H}) ; 1737(\mathrm{C}=\mathrm{O})$.

Dynamic Scanning Calorimetry. The glass transition temperatures $\left(\mathrm{T}_{\mathrm{g}} \mathrm{S}\right)$ were measured using a TA Instruments dynamic scanning calorimeter with a temperature ramp rate of $10^{\circ} \mathrm{C} / \mathrm{min}$ from -90 to $90^{\circ} \mathrm{C}$. Samples were carefully dried in a vacuum oven at $40{ }^{\circ} \mathrm{C}$ for $24 \mathrm{~h}$ prior to measurement. Each sample was measured three times and exhibited a single, distinct transition.

Rheology. All rheological measurements were performed on a Rheometric Scientific Advanced Rheometric Expansion System (ARES) controlled-strain rheometer using a $25 \mathrm{~mm}$ cone-and-plate geometry with a gap of $0.051 \mathrm{~mm}$. Tests with other tool geometries verified the results reported here are independent of the measurement apparatus. Dynamic measurements were performed in the linear viscoelastic regime with strain amplitude of $1 \%$. The testing temperature was controlled using a Peltier lower plate with a humidity cover and was varied from -20 to $30^{\circ} \mathrm{C}$.

\section{Results and Discussion}

Glass Transition Temperature. Table 1 lists the glass transition temperature for each of the samples studied. From these results, it is apparent that $\mathrm{T}_{\mathrm{g}}$ is a strong function of the end-group functionality and only a slight function of the generation number. For example, the $\mathrm{T}_{\mathrm{g}} \mathrm{s}$ for G4 PPI/MA and G5 PPI/MA differ by only a degree. The behavior for a given type of end group is consistent earlier studies of dendrimer glass transitions. ${ }^{9,13,14}$ These studies showed that the $\mathrm{T}_{\mathrm{g}}$ of a dendrimer increases with molecular weight for the first few generations but reaches a plateau around generation 4, above which the $\mathrm{T}_{\mathrm{g}}$ is essentially constant.

The $T_{g} s$ measured for the fourth- and fifth-generation dendrimers are higher by about $20^{\circ} \mathrm{C}$ from what has been reported by the manufacturer. ${ }^{7,15}$ Our values for our samples have been measured by two separate instruments at two different locations, the University of Delaware and the analytical analysis laboratory at

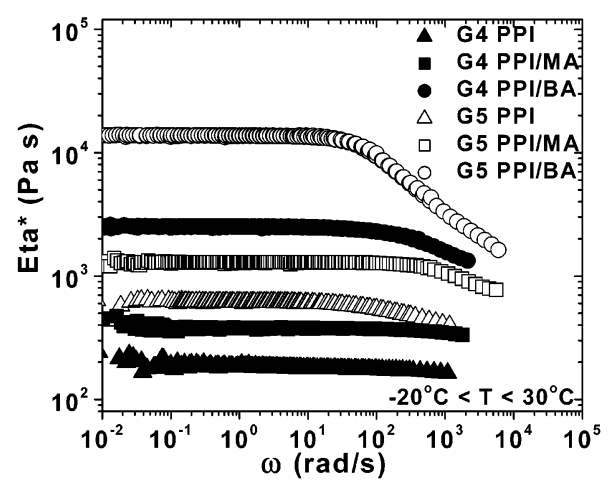

Figure 1. Dynamic viscosity as a function of frequency for all PPI dendrimers and derivatives. The data come from measurements over a $50^{\circ} \mathrm{C}$ temperature range that have been shifted to a common temperature of $0{ }^{\circ} \mathrm{C}$.

Dupont's Experimental Station, and hence will be used in the following analysis.

The derivatized dendrimers may be thought of as copolymers of propyleneimine and methyl or benzyl acrylate. As there is a single $\mathrm{T}_{\mathrm{g}}$ observed for the derivatized dendrimer, it is useful to compare it with predictions based on linear copolymers. For random copolymers, the Gordon-Taylor equation provides a prediction of the $\mathrm{T}_{\mathrm{g}}$ based on the $\mathrm{T}_{\mathrm{g}} \mathrm{S}$ of the individual components. ${ }^{16}$ The Gordon-Taylor constant, $k\left(=\Delta \alpha_{2} V_{2} /\right.$ $\Delta \alpha_{1} V_{1}$ ), is related to the change in the thermal expansion coefficient, $\Delta \alpha$, at $T_{g}$ and the specific volume, $V$, of both component polymers. The value of $\mathrm{k}$ required to fit the data ranges from 0.07 to 0.22 , with higher values for the BA derivatives than for the MA derivatives. These low values for $\mathrm{k}$ skew the overall $\mathrm{T}_{\mathrm{g}}$ in favor of the dendrimer and, considering the definition of $k$, suggest that, since the specific volumes are comparable, the change in the thermal expansion coefficient at $T_{g}$ is significantly greater for PPI dendrimers than for polyacrylates. Our measurements show that $\Delta \alpha$ for PPI is on the order of $5 \times 10^{-4} \mathrm{~K}^{-1}$, which is comparable to most linear polymers, ${ }^{19}$ suggesting that the GordonTaylor equation can at best be used only for fitting the data. A simpler expression, the Fox equation, ${ }^{17}$ al so provides a poor prediction of the modified dendrimer $\mathrm{T}$. This finding, that neither model can be used predictively, is not surprising, as the individual acrylate end groups would not be expected to have the same effect on the overall $\mathrm{T}_{\mathrm{g}}$ as if incorporated into linear copolymers. Thus, the thermal properties of the derivatized dendrimers suggest that incorporation of these monomers at the dendrimer end groups should have a less significant effect than incorporating them into a linear copolymer, for example.

Dynamic Viscosity. The measured dynamic viscosity of each sample as a function of frequency at a common temperature is plotted in Figure 1 . The zerofrequency dynamic viscosities, $\eta_{0}^{*}$, taken from these data are listed in Table 1 . These results show that the neat PPI dendrimer melts all exhibit a constant viscosity over a wide range of frequencies, but with increasing molecular weight, achieved through derivatization, frequency thinning becomes evident at higher frequencies. Steady shear rate data (not shown) verifies that the extended Cox-Merz rule $\left(\eta(\dot{\gamma})=\eta^{*}(\omega)\right)$ is valid for all samples.

It is relevant to determine whether the non-Newtonian behavior observed in the higher molecular weight samples is due to shear effects on the intermolecular 
Table 2. Peclet Number Analysis and Further Dendrimer Characterization

\begin{tabular}{lcccc}
\hline & $\begin{array}{c}\text { Peclet } \\
\text { number } \\
\text { at shear } \\
\text { thinning }\end{array}$ & $\begin{array}{c}\text { max } \\
\text { Peclet } \\
\text { number } \\
\text { achieved }\end{array}$ & $\begin{array}{c}\text { radius } \\
\text { (estd from } \\
\text { density) }(\AA)\end{array}$ & $\begin{array}{c}\text { surface } \\
\text { area } \\
\text { fraction }\end{array}$ \\
\hline G4 PPI & & 0.73 & 11.3 & 0.28 \\
G4 PPI/MA & & 5.7 & 14.8 & 0.74 \\
G4 PPI/BA & 3.3 & 160 & 17.6 & 0.74 \\
G5 PPI & 0.1 & 5 & 14.4 & 0.34 \\
G5 PPI/MA & 0.8 & 75 & 18.6 & 0.93 \\
G5 PPI/BA & 6.8 & 3400 & 22.0 & 0.94
\end{tabular}

a This represents the fraction of the dendrimer's surface area that is occupied by end groups. This is calculated using the molecular radius as calculated from the density and by estimating the size of the end groups from the bulk density of the monomers (i.e., ammonia, methyl acrylate, and benzyl acrylate).

microstructure or whether it results from shear-induced disentanglement, such as for a linear polymer melt above the entanglement $\mathrm{M}_{\mathrm{w}}$. Given the relatively low molecular weights and known gl obular structure, we do not anticipate significant molecular entanglement or shear-induced molecular deformation, which leaves intermolecular interactions as the source of shear thinning. The validity of this mechanism can be assessed as follows. Treating the dendrimer melt as a simple molecular fluid, the Peclet number, defined as the ratio of the shear to diffusive time scales, is

$$
\mathrm{Pe}^{*}=\frac{\mathrm{R}_{\mathrm{g}}{ }^{2} \omega}{\mathrm{D}_{\mathrm{s}}}=\frac{6 \pi \eta_{0}{ }^{*} \mathrm{R}_{\mathrm{g}}{ }^{3} \omega}{\mathrm{k}_{\mathrm{b}} \mathrm{T}}
$$

In the above, $D_{s}$ is the self-diffusion coefficient given by the Stokes-Einstein expression, $k_{b}$ is Boltzmann's constant, $\mathrm{T}$ is temperature, $\mathrm{R}$ is the dendrimer's radius, $\omega$ is the experimental frequency, and $\eta_{0} *$ is the zerofrequency dynamic viscosity. F or colloidal and molecular liquids, the transition to shear thinning is expected to occur at a Peclet number of order one, i.e., when the shear rate (or frequency) exceeds the molecule's characteristic diffusion rate. ${ }^{24}$ At this point, the microstructure is no longer near equilibrium but responds so as to reduce the viscosity. For these calculations we assume that the dendrimers are spheres and estimate $R_{g}=$ $(3 / 5)^{1 / 2} \mathrm{R}$ from the known molecular weight $M_{w}$ and the measured bulk melt density as $R=\left[\left(\mathrm{M}_{\mathrm{w}} /\left(\mathrm{N}_{\mathrm{A}} \rho(4 \pi / 3)\right)\right]^{1 / 3}\right.$, where $\mathrm{N}_{\mathrm{A}}$ is the Avogadro number.

Peclet numbers calculated at the point of frequency thinning and at the maximum frequency achieved in the experiment are given in Table 2. For those samples that show shear and frequency thinning, the Peclet number at the point of frequency thinning range from 0.1 to 6.8. For reference, colloidal dispersions show shear or frequency thinning for Peclet numbers of order 0.01-1. ${ }^{24}$ The sample G4 PPI/ MA shows evidence of frequency thinning at the highest frequencies, whereas the lowest viscosity sample, G4 PPI, just barely exhibits frequency thinning, in agreement with expectation. This analysis suggests that the shear thinning is due primarily to the shear effects on the intermolecular microstructure and is not a result of molecular entanglements.

In earlier studies by Uppuluri et al., 8 PAMAM dendrimers have also shown shear thinning in the melt, which was attributed to disruption of a structure formed by hydrogen bonding. We have applied a similar analysis on these results to calculate the Peclet number at the point of shear thinning for PAMAM dendrimers of generations 3-6. These values were calculated using the molecular radius measured by Prosa et al. in solution. ${ }^{21}$ The point of shear thinning occurred at Peclet numbers from 10 to 24 , suggesting qualitatively similar behavior as seen in our PPI melts. PAMAM dendrimers in solution, also studied by Uppuluri et al., show no shear thinning, ${ }^{25}$ a result consistent with the current analysis. The maximum Peclet numbers achieved during these measurements are several orders of magnitude lower $\left(\sim 10^{-4}\right)$ than that necessary for thinning to be observed.

The most prevalent thinning is observed in the sample of the highest molecular weight, G5 PPI/BA. The power law slope for the thinning regime is -0.46 , a value very close to that predicted by the Rouse model, -0.5 . F or comparison, many entangled polymers have slopes ranging from -0.6 to -0.75 .

Time-Temperature Superposition. The data shown in Figure 1 represent data taken over a wide temperature range that has been shifted to a common temperature using the principle of time-temperature superposition (TTS). The shift factors used to create these master curves were then fit to both the WLF and the Arrhenius equations. The parameters found from both fits are listed in Table 3. The WLF fits wereslightly better than the Arrhenius fits, a result that is expected for measurements taken within $100{ }^{\circ} \mathrm{C}$ of the glass transition temperature. ${ }^{19}$ The WLF parameters were used to calculate $f_{g}$, the fractional free volume at $T_{g}$, for each dendrimer. ${ }^{19} \mathrm{~F}$ or all six of the molecules studied here, $\mathrm{f}_{\mathrm{g}}$ appears to be roughly constant, ranging from 0.034 to 0.038 . These are all significantly larger than the value of 0.025 found for many linear polymers. ${ }^{19}$

This result is consistent with the expectation that end groups contribute a larger free volume than backbone monomers. Further, since the fraction of end groups is roughly independent of generation or functionalization for our series of dendrimers, it would be expected that the fractional free volume in the melt would be approximately constant. These observations are in agreement with earlier results for other dendrimers of generations 4-6. ${ }^{7-9}$ Our results, al ong with those previously published, demonstrate that the free volume of dendrimers is primarily a function of the branched architecture, and when the molecular weight is high enough (i.e., polymeric), the free volume does not depend

Table 3. Time-Temperature Superposition Parameters

\begin{tabular}{|c|c|c|c|c|c|c|c|}
\hline \multirow[b]{2}{*}{ sample } & \multirow{2}{*}{\multicolumn{5}{|c|}{ WLF }} & \multirow{2}{*}{$\frac{\text { Arrhenius }}{\mathrm{E}_{\eta}(\mathrm{kJ} / \mathrm{mol})}$} & \multirow[b]{2}{*}{ 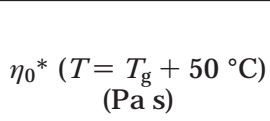 } \\
\hline & & & & & & & \\
\hline G4 PPI & 12.0 & 100 & 210 & 110 & 0.036 & 64.0 & 796 \\
\hline G4 PPI/MA & 12.3 & 73 & 216 & 143 & 0.035 & 74.5 & 929 \\
\hline G4 PPI/BA & 11.6 & 63 & 234 & 171 & 0.037 & 98.7 & 226 \\
\hline G5 PPI & 12.4 & 99 & 210 & 111 & 0.035 & 65.9 & 2800 \\
\hline G5 PPI/MA & 12.9 & 74 & 217 & 143 & 0.034 & 79.2 & 6540 \\
\hline G5 PPI/BA & 11.4 & 64 & 236 & 172 & 0.038 & 100.2 & 2360 \\
\hline
\end{tabular}



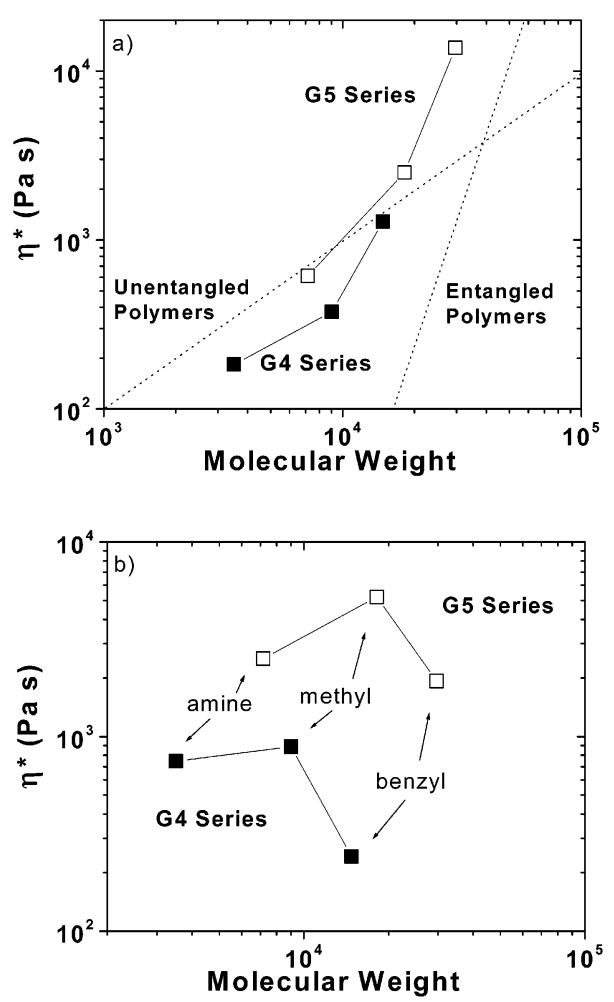

Figure 2. Zero-frequency dynamic viscosity as a function of molecular weight at (a) $\mathrm{T}=0{ }^{\circ} \mathrm{C}$ and (b) $\mathrm{T}=\mathrm{T}_{\mathrm{g}}+50^{\circ} \mathrm{C}$.

significantly on either the functionality of the end groups, the distance between branch points, or the generation of the dendrimer.

Dependence of Viscosity on Molecular Weight. In unentangled linear polymers the zero-shear viscosity is known to be directly proportional to molecular weight. In previously published work, a similar linear dependence on generation was observed for PBE dendrimers when corrected for free volume effects. ${ }^{9}$ F or PAMAM dendrimers, the viscosity increases more rapidly than this at lower generations but tends toward a linear dependence at higher generations. ${ }^{8}$

In this study we increase the molecular mass both by increasing the generation (G4-G5) and, more substantially, by end-group derivatization. Derivatization increases the mol ecular weight but also raises the glass transition temperature. Figure $2 \mathrm{a}$ is a plot of dynamic viscosity vs molecular weight for data shifted to an arbitrary temperature $\left(\mathrm{T}=0^{\circ} \mathrm{C}\right)$. This plot shows that the viscosity generally increases with molecular weight within a generation. Overall, the viscosity is not a smooth function of the molecular weight, as the G4 $\mathrm{PPI} / \mathrm{MA}$ dendrimer has a lower viscosity than the G5 PPI, despite the fact that its molecular weight is greater.

Figure $2 \mathrm{~b}$ shows the viscosity shifted to $50^{\circ} \mathrm{C}$ above the $T_{g}$ for each sample, which accounts for the different chemical compositions of the dendrimer copolymers. Both generations of dendrimers exhibit a viscosity maximum with molecular weight. Although there is a limited amount of data, there is a noteworthy resemblance to the familiar intrinsic viscosity vs generation number plots that show maxima for dendritic polymers. ${ }^{26}$ In analogy to the analysis of the intrinsic viscosity studies, a plausible explanation for our observation is that the functionalization of the end groups results in a more compact molecule.

To understand this unique behavior, we have cal culated a so-called surface area fraction of end groups for each molecule. The total surface area of the spherical dendrimer can be calculated from the radius determined from the density measurements. Then, using the $M_{w}$ and density of the acrylate monomers, the crosssectional area of the end groups can be estimated, approximating them as cylinders with $L / D=3$ (as deduced from molecular modeling). From these values, the ratio of the cross-sectional area of the acrylate end groups to the total surface area of the dendrimer is cal culated (see Table 2). This calculation suggests that, without significant backfolding, the periphery of the dendrimers would become substantially crowded upon end-group functionalization. The most extreme case is that of G5 PPI/BA, for which this fraction is nearly 1 . It is therefore likely that the dendrimers exhibit extensive backfolding, the degree of which increases with derivatization. In a recent publication, Zacharopoulos and $\mathrm{E}$ conomou ${ }^{27}$ report the results of molecular dynamics simulations on PPI dendrimers in the melt in order to assess their internal structure and morphology. In support of our experimental findings, these simulations suggest that increasing the generation of the dendrimer leads to a more space-filling structure that results in less interpenetration of dendrimer molecules.

Dynamic Moduli. Parts $a$ and $b$ of Figure 3 show TTS shifted dynamic moduli data for two representative samples: underivatized G4 PPI and G5 PPI/BA, respectively. The underivatized sample (Figure $3 a$ ) exhibits low elasticity that is typical of an unentangled polymer melt. There is no apparent entanglement plateau or crossover point over the range of frequencies measured. The loss modulus has a power law slope of one over the entire range of frequencies. Even for the most viscous sample, G5 PPI/BA (Figure 3b), the loss modulus, G",
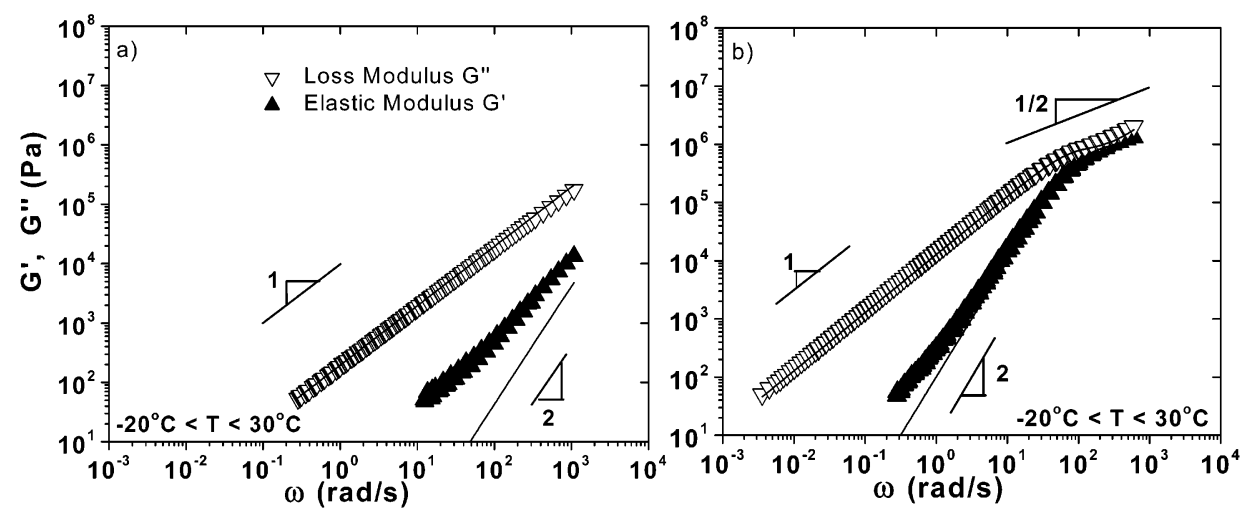

Figure 3. Dynamic moduli of (a) underivatized fourth-generation PPI dendrimer (G4 PPI), and (b) the benzyl acrylate derivatized fifth-generation dendrimer (G5 PPI/BA). The solid lines are fits to the Rouse model. 


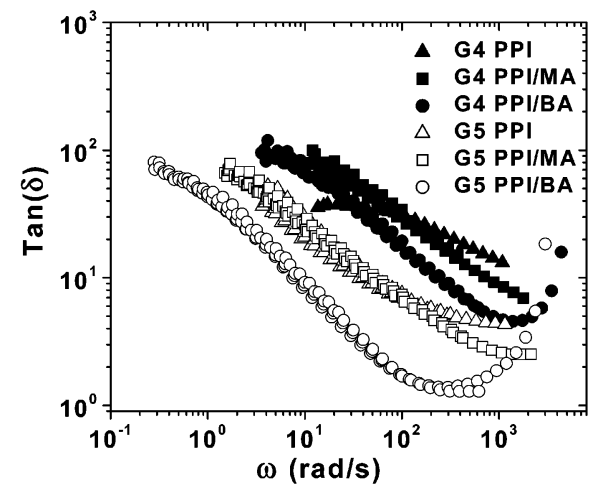

Figure 4. $\operatorname{Tan}(\delta)$ as a function of frequency for each sample.

is always observed to be larger than the elastic modulus, $\mathrm{G}^{\prime}$, as would be expected in the absence of entanglement coupling.

Also shown in these plots are fits of the dynamic moduli to the Rouse model. F or the G5 PPI/BA sample, the Rouse model fits the data with $\tau=0.01 \mathrm{~s}$ as the longest relaxation time. At high frequencies $\mathrm{G}^{\prime}$ and $\mathrm{G}^{\prime \prime}$ both increase with a slope of $1 / 2$, as expected for unentangled polymer melts; however, the range of the data is limited at higher frequencies. This sample shows liquidlike terminal behavior with slopes of one and two for $G^{\prime}$ and $G^{\prime \prime}$, respectively, at intermediate frequencies. However, at the lowest frequencies $G^{\prime}$ begins to deviate positively from Rouse behavior. The slightly higher elastic modulus may suggest that there are other relaxation modes at these lower frequencies.

The dynami c elastic modulus, $\mathrm{G}^{\prime}$, of the underivatized dendrimer is greater than that expected for the Rouse model, and liquid terminal behavior is not observed. F or reference, a comparison between the dynamic behavior of all samples can be found in Figure 4, a plot of $\tan (\delta)$, the ratio of $G^{\prime \prime}$ to $G^{\prime}$, vs frequency.

Previously published findings for PAMAM dendrimers of G1-G6 demonstrate Rouse-like linear viscoelasticity as well as the frequency thinning observed here. Further increasing generation number leads to relatively greater elastic behavior, eventually resulting in $\tan (\delta)<1$ at high frequencies for the largest generation dendrimers. In comparison, our PPI dendrimers and dendrimer copolymers have $\tan (\delta)>1$, but tending toward one with increasing molecular weight.

\section{Conclusions}

End-group functionalization has a substantial effect on the molecular structure and macroscopic behavior of PPI dendrimer copolymer melts. Most notably, however, the effect of functionalization on the glass transition temperature is found to be not as significant for these dendritic copolymers as would be expected for a linear copolymer. This may be related to the fractional free volume, derived from the thermorheological measurements, which is substantially larger than that for linear polymers and nearly independent of the endgroup derivatization.

Measurements of dendrimer melt rheology are consistent with that of unentangled polymers but are influenced considerably by the conformational changes that accompany end-group derivatization. Non-N ewtonian behavior is seen as the molecular weight increases but can be rationalized in terms of small molecule and dispersion rheology. The addition of bulky end groups increases the absolute viscosity, but when the shifting of $\mathrm{T}_{\mathrm{g}}$ is accounted for, the zero-shear viscosity exhibits a maximum with $\mathrm{M}_{\mathrm{w}}$. This can be traced back to the increased steric crowding and densification of the molecule, which leads to a decrease in intermolecular overlap.

Acknowledgment. Financial support from the DuPont Company through the Grants in Aid of E ducation program is gratefully acknowledged. B.M.T. acknowledges support from Hercules, I nc. We also acknowledge the support of the National I nstitute of Standards and Technology, U.S. Department of Commerce, in providing facilities used in this work. This material is based upon activities supported by the National Science F oundation under Agreement DMR-9986442.

\section{References and Notes}

(1) Dvornic, P. R.; Tomalia, D. A. Curr. Opin. Colloid Interface Sci. 1996, 1, 221-235.

(2) Dykes, G. M. J . Chem. Technol. Biotechnol. 2001, 76, 903918.

(3) Matthews, O. A.; Shipway, A. N.; Stoddart, J . F. Prog. Polym. Sci. 1998, 23, 1-56.

(4) Bosman, A. W.; J anssen, H. M.; Meijer, E. W. Chem. Rev. 1999, 99, 1655-1688.

(5) Boogh, L.; Pettersson, B.; Manson, J. A. E. Polymer 1999, 40, 2249-2261.

(6) Hawker, C. J .; Hedrick, J . L.; Miller, R. D.; Volksen, W. MRS Bull. 2000, 25, 54-58.

(7) Sendijarevic, I.; McHugh, A. J. Macromolecules 2000, 33, 590-596.

(8) Uppuluri, S.; Morrison, F. A.; Dvornic, P. R. Macromolecules 2000, 33, 2551-2560.

(9) Farrington, P. J .; Craig, J . H.; F réchet, J . M. J .; Mackay, M. E. Macromolecules 1998, 31, 5043-5050.

(10) Bodnar, I.; Silva, A. D.; Deitcher, R. W.; Weisman, N. E.; Kim Y. H.; Wagner, N. J .J . Polym. Sci., Part B: Polym. Phys. 2000, 38, 857-873.

(11) Bodnar, I.; Silva, A. D.; Kim, Y. H.; Wagner, N. J . J . Polym Sci., Part B: Polym. Phys. 2000, 38, 874-882.

(12) van Duijvenbode, R. C.; Rajanayagam, A.; Koper, G. J . M.; Baars, M.; de Waal, B. F. M.; Meijer, E. W.; Borkovec, M. Macromolecules 2000, 33, 46-52.

(13) Stutz, H. J . Polym. Sci., Part B: Polym. Phys. 1995, 33, 333340.

(14) Wooley, K. L.; Hawker, C. J .; Pochan, J . M.; Frechet, J . M. J. Macromol ecules 1993, 26, 1514-1519.

(15) DSM. Properties of Astramol Dendrimers. http://www3.dsm com/astramol/properties/ en/index.pl?f=properties.htm. April 29, 2002.

(16) Hale, A.; Bair, H. E. Polymer Blends and Block Copolymers. In Thermal Characterization of Polymeric Materials; Turi, E. A., Ed.; Academic Press: New York, 1997.

(17) Emran, S. K.; Liu, Y.; Newkome, G. R.; Harmon, J. P. J. Polym. Sci., Part B: Polym. Phys. 2001, 39, 1381-1393.

(18) Brandrup, J ., Immergut, E. H., Grulke, E. A., Eds.; Polymer Handbook, 4th ed.; Wiley: New York, 1999.

(19) Ferry, J. D. Viscoelastic Properties of Polymers, 3rd ed. Wiley: New York, 1980; p 641.

(20) Evmenenko, G.; Bauer, B. J .; Kleppinger, R.; Forier, B.; Dehaen, W.; Amis, E. J .; Mischenko, N.; Reynaers, H. Macromol. Chem. Phys. 2001, 202, 891-899.

(21) Prosa, T. J .; Bauer, B. J .; Amis, E. J .; Tomalia, D. A.; Scherrenberg, R. J . Polym. Sci., Part B: Polym. Phys. 1997 35, 2913-2924.

(22) Potschke, D.; Ballauff, M.; Lindner, P.; Fischer, M.; Vogtle F. Macromolecules 1999, 32, 4079-4087.

(23) Potschke, D.; Ballauff, M.; Lindner, P.; Fischer, M.; Vogtle, F. Macromol. Chem. Phys. 2000, 201, 330-339.

(24) Russel, W.; Saville, D.; Schowalter, W. Colloidal Dispersions; Cambridge University Press: New York, 1989.

(25) Uppuluri, S.; Keinath, S. E.; Tomalia, D. A.; Dvornic, P. R. Macromolecules 1998, 31, 4498-4510.

(26) Mourey, T. H.; Turner, S. R.; Rubenstein, M.; Frechet, J . M. J .; Hawker, C. J .; Wooley, K. L. Macromolecules 1992, 25, 2401-2406.

(27) Zacharopoulos, N.; Economou, L. G. Macromolecules 2002, 35, 1814-1821.

$\mathrm{MA020801 \textrm {H }}$ 